\title{
Iniciação científica com pesquisas qualitativas: relato da experiência de um grupo de professores e alunos de Medicina
}

Undergraduate research with qualitative methods: report of the experience of a group of teachers and medical students

La iniciación científica con la investigación cualitativa: un relato de experiencia de un grupo de profesores y estudiantes de Medicina

Bruno José Barcellos Fontanella**, Débora Gusmão Melo², Carla Maria Ramos Germano ${ }^{3}$, Bianca Mayumi Watanabe ${ }^{4}$, César Seiji Setoue ${ }^{5}$, Débora Bonato ${ }^{6}$, Fernanda Rodrigues da Silva7, José Eduardo Vitorino Galon $^{8}$, Karina Nogueira Dias Secco ${ }^{9}$, Mariana Bueno da Silva San Felice ${ }^{10}$, Taysa Moreira'

Palavras-chave: Pesquisa Científica e Desenvolvimento Tecnológico

Educação Médica Pesquisa Qualitativa Atenção Primária à Saúde Scientific Research and Technological Development Education, Medical Qualitative Research Primary Health Care

\section{Resumo}

Objetivou-se relatar e discutir as experiências de um grupo de professores e alunos de graduação de Medicina sobre os estágios de iniciação científica, realizados por meio de projetos de pesquisa com métodos qualitativos, parte deles tendo a Atenção Primária à Saúde como campo de pesquisa. Contextualizando o relato, acentuou-se a história relativamente recente da iniciação científica no Brasil e, em nível mundial, a também recente utilização em mais ampla escala dos métodos qualitativos em saúde. 0 relato de experiência se estruturou a partir do fluxograma do processo de trabalho seguido pelos estágios de iniciação científica. Destacou-se ter havido uma relativa autonomia dos estudantes em relação à coleta de dados, mas, por outro lado, maior dependência em relação aos seus orientadores no momento de analisar e interpretar os achados. Por meio desses estágios, acredita-se que se valoriza a rede de significados presentes no processo saúde-doença-cuidado, em particular na Atenção Primária à Saúde, considerando que uma progressiva compreensão científica desse processo complexo ajuda a aperfeiçoar uma prática médica atenta às plenas necessidades de pacientes e comunidades.

\section{Abstract}

This paper was aimed at reporting and discussing the experiences of a group of teachers and students of a medical undergraduate course about medical student research, achieved through research projects with qualitative methods, some of them having the Primary Health Care as a field of research. Contextualizing the report, it was emphasized the recent history of medical student research in Brazil
Departamento de Medicina da Universidade Federal de São Carlos (UFSCar). bruno@ufscar.br

2Departamento de Medicina da Universidade Federal de São Carlos (UFSCar).dgmelo@ufscar.br

3Departamento de Medicina da Universidade Federal de São Carlos (UFSCar). cgermano@ufscar.br

${ }^{4}$ Universidade Federal de São Carlos (UFSCar). bianca_watanabe@hotmail.com

5Universidade Federal de São Carlos (UFSCar). csetoue@gmail.com

EUniversidade Federal de São Carlos (UFSCar). debibonato@yahoo.com.br

7Universidade Federal de São Carlos (UFSCar). fer_rodriguesilva@hotmail.com

\&Universidade Federal de São Carlos (UFSCar). jose.eduardo.galon@gmail.com

ฯUniversidade Federal de São Carlos (UFSCar). karina_nds@hotmail.com

10Universidade Federal de São Carlos (UFSCar). marybueno@gmail.com

${ }^{11}$ Universidade Federal de São Carlos (UFSCar). taysacms@hotmail.com

${ }^{\star}$ Autor correspondente.

Fonte de financiamento: nenhuma.

Conflito de interesses: declararam não haver.

Recebido em: 28/09/2011

Aprovado em: 19/12/2011 
and also the recent use of qualitative methods in health worldwide. The experience report was structured from a basic flowchart of the working process followed by the research projects internships. It is noteworthy that there was an autonomy in relation to data collection but, on the other hand, a greater reliance on their advisers when analyzing and interpreting the findings. Through these undergraduate stages, it is valued the network of meanings present in the health-illness-care process, particularly in Primary Health Care, considering that a progressive scientific understanding of this complex process helps to improve a medical practice effectively attentive to the full health needs of patients and communities.

Palabras clave: Investigación Científica y Desarrollo Tecnológico Educación Médica Investigación Cualitativa Atención Primaria de Salud

\section{Resumen}

El objetivo fue presentar y discutir las experiencias de un grupo de profesores y estudiantes de Medicina en las etapas de iniciación científica realizadas por medio de proyectos de investigación utilizando métodos cualitativos, algunos de ellos con la Atención Primaria de Salud como campo de la investigación. Contextualizando el relato, el énfasis está en la historia relativamente reciente de la iniciación científica en Brasil, y lo también uso reciente y en gran escala de métodos cualitativos en la salud en todo el mundo. El relato de la experiencia se estructuró a partir del diagrama de flujo del proceso de trabajo seguido por las etapas de la iniciación científica. Es de destacar que hubo una relativa autonomía de los estudiantes respecto a la recopilación de datos, pero por otro lado, una mayor dependencia de sus orientadores en la revisión e interpretación de los resultados. A través de estas etapas, se considera que los valores de la red de significados presentes en la salud-enfermedad-cuidado son valorizados, en especial en la Atención Primaria de Salud, mientras que una progresiva comprensión científica de este complejo proceso ayuda a mejorar la práctica médica atenta a las completas necesidades de los pacientes y las comunidades.

\section{Introdução}

Neste relato, foram discutidas algumas experiências de um grupo de professores e estudantes de graduação em Medicina sobre iniciação científica (IC), realizada com projetos de pesquisa com métodos qualitativos, parte dos quais tendo como campo de pesquisa a Atenção Primária à Saúde (APS).

Partiu-se da premissa de que os estágios deste tipo podem apresentar dificuldades adicionais àquelas representadas por IC com outros métodos, pois introduzem os estudantes às bases da metodologia científica pela via dos modelos teórico-interpretativos das Ciências Humanas, menos enfatizados nos currículos médicos.

\section{IC nos cursos de medicina no brasil}

A IC no Brasil começou em 1988, quando o Conselho Nacional de Desenvolvimento Científico e Tecnológico (CNPq), órgão federal criado em 1951, instituiu o Programa Institucional de Bolsas de Iniciação Científica (PIBIC). Antes, somente os pesquisadores graduados tinham acesso a bolsas de estudo. Atualmente, várias fundações estaduais de amparo à pesquisa também contribuem com bolsas de IC em seus Estados ${ }^{1}$.

Um estudo realizado por ocasião do Exame Nacional de Desempenho dos Estudantes (ENADE), com egressos de vários cursos de graduação, incluindo Medicina, revelou que os estudantes tinham tido acesso à IC em mais de $70 \%$ das Instituições de Ensino Superior (IES) e que também cerca de $70 \%$ dos alunos participaram de IC. Tais índices podem ser considerados altos para uma atividade implantada apenas re- centemente no País. O mesmo estudo revelou que $44 \%$ dos estudantes concluintes das IES públicas e $50 \%$ das particulares consideraram que seus projetos de IC contribuíram ampla ou parcialmente em suas formações, ao passo que $20 \%$ manifestaram que a IC teve pouca ou nenhuma relevância ${ }^{2}$.

Não foram encontrados estudos com dados sobre o alcance dos programas de IC em uma grande amostra de cursos de Medicina. Um estudo realizado com estudantes de Medicina do sexto ano de seis escolas médicas de quatro Estados brasileiros ( $n=413$ ) mostrou que $68 \%$ deles participaram de IC. Nesse mesmo estudo, $84 \%$ dos estudantes defenderam a obrigatoriedade da IC na graduação, e foram apontadas três dificuldades principais para realização de pesquisas: pouco estímulo institucional, carência de recursos financeiros e insuficiente número de docentes qualificados ${ }^{3}$. Outro aspecto a ser considerado é que a adesão dos alunos de Medicina à IC tende a decair nos últimos anos de suas formações ${ }^{4}$.

A IC pode ser considerada um instrumento de formação de recursos humanos qualificados. Nos cursos de Medicina, provavelmente estimula a avaliação crítica da literatura médica, contribuindo posteriormente para a educação profissional continuada. Também existe a percepção de que o médico que se dedicou anteriormente à pesquisa seria dotado de melhor juízo crítico, o que o auxiliaria na feitura de diagnósticos e análises para tomadas de decisões 5 . É possível que a IC ajude o estudante de Medicina a incorporar algumas atitudes, como fazer perguntas, avaliar dados, usar novas técnicas, desenvolver metodologias e promover pesquisas científicas responsáveis ${ }^{6}$.

As escolas médicas caminham para introduzir em seus currículos atividades educacionais optativas ou obrigatórias que abordem conhecimentos metodológicos básicos, asso- 
ciadas ou não ao desenvolvimento de um projeto de pesquisa. Isso parece ser uma das novidades da educação médica atual $^{5}$. No Brasil, algumas escolas já possuem disciplinas de IC em seus currículos ${ }^{4,7,8}$.

\section{Métodos qualitativos de pesquisa no cuidado à saúde}

Os métodos qualitativos de pesquisa se desenvolveram a partir do início do século 20, sobretudo com as contribuições da antropologia cultural, fenomenologia e psicanálise. Naquele momento sócio-histórico, a Medicina procurava consolidar-se como científica ao fundamentar-se, particularmente, nos conhecimentos biológicos significativamente alavancados ao longo do século 19. Neste início das Ciências Médicas modernas, as Ciências Humanas colaboraram relativamente menos. Pelo menos até a década de 1960, as dificuldades neste diálogo foram compartilhadas pelas próprias Ciências Sociais, as quais balizavam suas preocupações com as questões do processo saúde-doença nos próprios conhecimentos biomédicos, privilegiando o estudo, por exemplo, sobre o quanto e por quais razões as pessoas se adequavam, ou não, ao que a Medicina delimitava e instituía como desejável ${ }^{9}$.

Com a progressiva mudança no perfil epidemiológico dos problemas que acometem as populações, as doenças crônico-degenerativas passaram a exigir uma interação clínico-paciente mais próxima e prolongada. A "voz" dos pacientes passa a ser tão valorizada quanto à dos médicos e outros profissionais de saúde, promovendo uma retomada histórica do interesse pelas narrativas dos pacientes sobre seus problemas, algo próximo ao modelo de relação médico-paciente vigente até meados do século $19^{10}$. Assim, as pesquisas qualitativas começam a ser progressivamente valorizadas como um meio de compreender o que se passa com os usuários dos sistemas de saúde, seus familiares e seus cuidadores formais. Atualmente não parece haver oposição à ideia de que um tratamento científico adequado aos 'significados' psicoculturais do processo saúde-doença-cuidado é de interesse ao setor saúde.

No Brasil, esta perspectiva será provavelmente fortalecida de modo progressivo, à medida que o Sistema Único de Saúde (SUS) - particularmente a APS - procura atingir a universalização do cuidado, incluindo grupos populacionais desprovidos até recentemente ou até o momento de uma atenção sistemática, longitudinal e de qualidade. Esses grupos, se incorporados ao sistema, precisarão ser 'ouvidos' atentamente. Além disso, a área do cuidado à saúde sempre precisará conhecer as representações e experiências subjetivas de pacientes e profissionais, pois continuará se defron- tando com uma realidade empírica processual ${ }^{11}$. Diversidades socioculturais, fenômenos epidemiológicos diversos e mudanças tecnológicas na área da saúde trarão, continuamente, repercussões nas subjetividades dos indivíduos, merecendo por isso um olhar compreensivo e interpretativo das ciências. Assim, os empreendimentos investigativos envolvendo os métodos qualitativos são, não apenas desejáveis, mas também necessários à continuidade do progresso científico da área médica.

\section{Nota sobre o método de elaboração do presente relato}

Os Quadros 1 e 2 fornecem uma caracterização acadêmica dos autores, três deles orientadores (denominados a partir deste ponto de professores) e oito deles orientados (denominados estudantes). Com a proximidade da finalização de alguns estágios de IC, este grupo se motivou a refletir sobre suas experiências.

Seus textos pessoais (corpus que totalizou cerca de 10.500 palavras) foram sistematizados na forma de uma metanarrativa, ou seja, de uma narrativa que se derivou de outras, procurando manter as reflexões individuais originais. A metanarrativa foi revista algumas vezes e a versão final, validada por todos, será logo apresentada.

As diversas etapas do fluxograma utilizado nas pesquisas de IC foram numeradas conforme consta na Figura 1, sendo que tais números correspondem aos itens desenvolvidos a seguir.

\section{Desenvolvimento do relato}

\section{(1) Motivações dos professores e seleção dos estudantes}

O departamento universitário a que os professores se vinculam completa seis anos de funcionamento em 2012, encontrando-se em um estágio de pouca maturidade institucional. Não conta com um Programa de Pós-Graduação (PPG) stricto sensu diretamente vinculado a ele, de modo que o início das atividades de pesquisa tem ocorrido, fundamentalmente, por meio da IC.

Sendo assim, parte das motivações das professoras que não tinham experiência anterior em pesquisas qualitativas deveu-se a esse estatuto profissional atual. Ainda sem condições plenas de desenvolverem linhas de pesquisa nas áreas de suas formações de pós-graduação (Quadro 2), investiram parte de seus esforços em investigações qualitativas, que não exigem grande infraestrutura de equipamentos e serviços, 
Quadro 1. Caracterização acadêmica do grupo de estudantes envolvidos nos trabalhos de iniciação científica do presente relato de experiência*.

\begin{tabular}{|c|c|c|c|c|c|c|c|}
\hline Estudante & $\begin{array}{l}\text { Ano do curso em que } \\
\text { começou e em que está }\end{array}$ & Bolsista & $\begin{array}{c}\text { Propôs o tema } \\
\text { do projeto? }\end{array}$ & $\begin{array}{c}\text { Já apresentou } 0 \\
\text { trabalho em eventos? }\end{array}$ & Objeto de estudo & Campo de estudo & $\begin{array}{l}\text { Etapa do projeto em } \\
\text { que se encontra }\end{array}$ \\
\hline A & $2^{\circ} / 5^{\circ}$ & $\mathrm{CNPq}$ & Não & Sim & $\begin{array}{l}\text { Significados psicoculturais do beber } \\
\text { e torcer em evento esportivo. }\end{array}$ & Campus universitário & $\begin{array}{l}\text { Artigo em avaliação } \\
\text { em periódico }\end{array}$ \\
\hline B & $2^{\circ} / 4^{\circ}$ & Fapesp & Não & Sim & $\begin{array}{l}\text { Representações sociais da } \\
\text { Síndrome de Down entre membros } \\
\text { de Equipes de Saúde da Família. }\end{array}$ & USF & Redigindo artigo \\
\hline C & $2^{\circ} / 2^{\circ}$ & CNPq & Não & Não & $\begin{array}{c}\text { Percepções de pacientes } \\
\text { tireoidectomizados sobre suas } \\
\text { qualidades de vida. }\end{array}$ & Ambulatório & Coletando dados \\
\hline D & $2^{\circ} / 5^{\circ}$ & CNPq & Não & Sim & $\begin{array}{l}\text { Significados psicoculturais } \\
\text { da indumentária utilizada por } \\
\text { profissionais de saúde. }\end{array}$ & USF & $\begin{array}{l}\text { Artigo aprovado para } \\
\text { publicação }\end{array}$ \\
\hline$E$ & $2^{\circ} / 3^{\circ}$ & $\mathrm{CNPq}$ & Não & Sim & $\begin{array}{c}\text { Representações sociais do } \\
\text { daltonismo entre estudantes } \\
\text { universitários daltônicos. }\end{array}$ & Campus universitário & Redigindo artigo \\
\hline $\mathrm{F}$ & $2^{\circ} / 5^{\circ}$ & Não & Não & Sim & $\begin{array}{l}\text { Significados psicoculturais de fumar } \\
\text { tabaco na gestação. }\end{array}$ & USF & $\begin{array}{l}\text { Artigo em avaliação } \\
\text { em periódico }\end{array}$ \\
\hline G & $2^{\circ} / 4^{\circ}$ & Fapesp & Sim & Sim & $\begin{array}{c}\text { Significados psicoculturais da } \\
\text { atuação dos palhaços para } \\
\text { pacientes hospitalizados. }\end{array}$ & Hospital & Redigindo artigo \\
\hline
\end{tabular}

*Um dos estudantes descontinuou seu trabalho de iniciação científica, embora tenha colaborado para o presente relato. Compartilhava do mesmo objeto de estudo do estudante C

Quadro 2. Caracterização acadêmica do grupo de professores (médicos) envolvidos nos trabalhos de iniciação científica.

\begin{tabular}{|lccc|}
\hline Professor & Área do Doutorado (ano de conclusão) & Tempo na carreira de professor universitário e em PPG* & Experiência prévia com pesquisas qualitativas \\
\hline A & Psicologia médica e da saúde (2000) & $7 / 3$ anos & Sim \\
B & Fisiologia e Biologia Molecular (2006) & $6 / 2$ anos & Não \\
C & Epidemiologia genética de populações humanas (2006) & $9 / 4$ anos & Não \\
\hline
\end{tabular}

*PPG: Programas de Pós-Graduação.

além de terem custo relativamente baixo. Motivaram-nas também a possibilidade de expansão de suas pesquisas utilizando abordagens sensíveis aos universos psicoculturais dos sujeitos envolvidos no processo saúde-doença-cuidado.

De outro lado, um dos professores autores doutorou-se com uma pesquisa clínico-qualitativa e atualmente procura consolidar uma linha de pesquisa a partir desse tipo de abordagem.

Os interesses dos três professores convergiram por terem tido especializações médicas em áreas clínicas (Genética Médica, Pediatria e Psiquiatria), acumulando experiências de cuidado clínico a pacientes, algo importante à formulação de problemas de pesquisa qualitativa que versem sobre o cuidado cotidiano à saúde e contemplem o estudo dos significados psicoculturais. Assim, embora nem todos tivessem experiência anterior com o método, desenvolveram projetos cujos objetos de estudo e problemas de pesquisa foram definidos a partir de seus exercícios clínicos.

O trabalho de apropriação dos métodos qualitativos de pesquisa em saúde foi e tem sido considerado frutífero por este grupo, em particular para as duas professoras sem experiências prévias com este tipo de investigação. Elas passaram a investir parte do seu tempo de estudo nesta metodologia, com a qual não tinham familiaridade, e trabalharam nos pro- jetos sempre em conjunto com o professor mais experiente. Deste empenho emergiu o reconhecimento de que para se desenvolver pesquisa qualitativa é essencial rigor científico, delineamento cuidadoso da metodologia e competência teórica dos pesquisadores envolvidos, especialmente para análise e interpretação dos dados coletados. Um dos subprodutos destas parcerias foi a proposta de um refinamento metodológico da técnica de fechamento amostral em pesquisas qualitativas, publicada numa revista de saúde pública nacional ${ }^{12}$.

Formulados os problemas de pesquisa, partiu-se para a viabilização dos projetos. Na seleção dos estudantes, os professores procuraram avaliar, sobretudo, indicadores de capacidade de iniciativa, entusiasmo e comprometimento com o projeto. Curiosamente, todos os estudantes selecionados encontravam-se no segundo ano de graduação quando começaram a se envolver com as pesquisas. $\mathrm{O}$ fato de frequentarem um curso que desenvolve atividades educacionais na APS desde o primeiro ano pode tê-los sensibilizado para os problemas que frequentemente ocorrem nos diferentes ambientes de assistência à saúde e para os fenômenos envolvidos no processo saúde-doença-cuidado.

Ao longo dos trabalhos, percebeu-se que associar alunos de IC a uma pesquisa impõe uma restrição ao tamanho do projeto a ser desenvolvido, uma vez que não podem ter dedicação inte- 
Figura 1. Fluxograma dos trabalhos de pesquisa e passos respectivos do processo de iniciação científica utilizando método qualitativo.

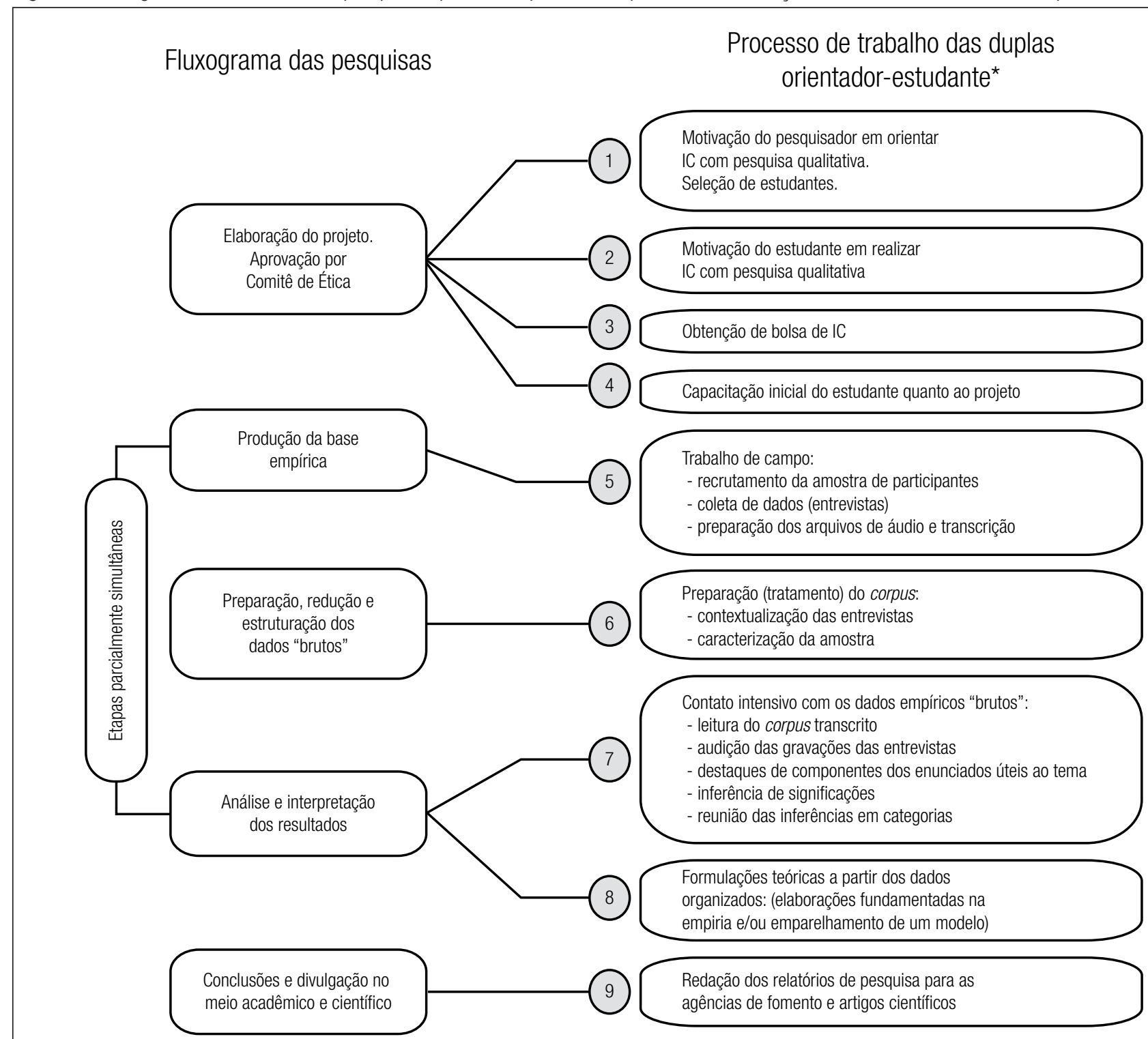

*Motivações, tarefas e procedimentos. Supõe-se, em todas as fases, haver supervisão direta dos trabalhos dos estudantes.

(X) Pontos discutidos no texto.

gral à pesquisa e dispõem, geralmente, de apenas um ano para terminá-la. Entretanto, foi chamativa aos professores, em geral, a alta qualidade do material empírico coletado pelos estudantes, possibilitando desdobramentos analíticos.

\section{(2) Motivações dos estudantes}

Embora as pesquisas qualitativas em saúde possam abranger aspectos não-clínicos, no presente caso as pesquisas relacionaram-se à clínica, envolvendo pacientes, potenciais pacientes ou seus cuidadores formais.
Essa característica dos projetos fez com que os estudantes se sentissem interessados pelos temas, curiosos em conhecer a resposta que seria dada à questão de pesquisa. Ter maior contato com as pessoas, conversando e discutindo temas relevantes, foi valorizado como um possível acréscimo às suas vidas profissionais futuras. Valorizou-se a oportunidade de se envolver no estudo de um determinado problema de saúde sob a perspectiva dos sujeitos pesquisados, o que não aconteceria se a IC consistisse em coleta de dados mais objetivos e paramétricos.

Apenas uma das estudantes iniciou sua IC a partir de um tema que não era, inicialmente, proposto pelo seu orientador; o fato de já conhecer e ter interesse pessoal no assun- 
to (atuação de palhaços em hospitais) facilitou a escolha do tema e da questão da pesquisa pela própria estudante.

É chamativo que alguns dos estudantes souberam sobre a possibilidade de uma formação inicial na prática de ciências apenas depois de ingressarem na universidade. O Ensino Médio não lhes parece ter anunciado esta possibilidade.

\section{(3) Questões relativas às bolsas de IC}

Seis dos oito estudantes receberam bolsa de IC (Quadro 1). Além de perceberem-na como um incentivo positivo, os estudantes consideram que a bolsa influenciou no consentimento de alguns participantes, como se o aval da instituição financiadora aumentasse a percepção de seriedade e credibilidade do trabalho. Os bolsistas perceberam-se também mais pressionados para o cumprimento do cronograma, em razão dos prazos de apresentação e envio do relatório para a agência financiadora, ao final de um ano de trabalhos.

\section{(4) Capacitação inicial do estudante quanto ao projeto de pesquisa}

O curso de graduação frequentado pelos estudantes é baseado na estratégia do aprendizado baseado em problemas, algo percebido pelos alunos como facilitador para a busca e a análise da bibliografia relacionada ao tema do projeto. Consideram também que a formação que recebem, privilegiando uma abordagem biopsicossocial em todas as atividades educacionais, facilitou a compreensão das justificativas das pesquisas nas quais estavam se inserindo, motivando-os ao estudo e à realização das tarefas.

Uma das táticas utilizadas na orientação foi a realização de seminários sobre metodologia de pesquisa qualitativa. Embora indispensável, a introdução dos estudantes às abstrações deste universo de discussão metodológica (cuja prática correspondente só iria ocorrer num momento futuro, durante a execução da pesquisa) foi percebido como difícil e cansativo.

\section{(5) Trabalho de campo}

Dentre as pesquisas, cujas coletas de dados já terminaram, o recrutamento de participantes e as próprias entrevistas foram encargos dos estudantes, processo supervisionado pelos orientadores.

De modo geral, efetivar este recrutamento foi considerado difícil e penoso. As pesquisas já terminadas abordaram diferentes populações: pacientes e profissionais de Unidades de Saúde da Família (USF), pacientes hospitalizados e estudantes universitários, tendo variado as dificuldades para chegar aos participantes e obter suas aquiescências, de acordo com a população abordada. Alguns profissionais, por exemplo, que de início concordaram em ser entrevistados em uma investigação de representações sociais sobre certa condição genética, esquivaram-se posteriormente. Alguns pacientes foram percebidos como tendo dificuldades de entender e aceitar participar, aparentemente por vergonha de conversar e aceitar gravar a entrevista. Por vezes, quando a amostra foi composta de sujeitos com determinada condição clínica, houve dificuldade para identificar os pacientes registrados nas USF e localizá-los nas comunidades, algo posteriormente contornado a partir da indicação dos trabalhadores das Unidades.

Em pesquisas qualitativas, pode haver flexibilidade no processo de amostragem, sobretudo porque não precisa ser aleatória. Isto fez com que se recorresse a alternativas para captar elementos amostrais. Em geral, recorreu-se a pacientes e profissionais dos próprios locais de estágio curricular dos estudantes.

Com relação às entrevistas, os estudantes perceberam-se suficientemente aculturados com as problemáticas pesquisadas. A grande variação de tempo de entrevista (de 5 a 80 minutos) pareceu se dever principalmente aos entrevistados ou às temáticas abordadas (por vezes percebidas como difíceis para os participantes) do que à capacidade dos entrevistadores em perscrutarem seus entrevistados.

Por se tratar de um encontro entrevistador-entrevistado, em que a demanda está com o entrevistador (ao contrário de uma entrevista clínica, em que a demanda é do paciente), experienciou-se apreensão e certa insegurança para entrevistar os voluntários. Entrevistados "monossilábicos" geraram incômodos, havendo por vezes a sensação, por parte dos estudantes, de não terem capacidade de ajudar o entrevistado a se expressar. No entanto, os estudantes também tiveram a sensação de evolução entre uma entrevista e outra, devido ao aperfeiçoamento que a prática traz à técnica empregada nas entrevistas semidirigidas.

Os estudantes começaram as atividades de IC no segundo ano do curso, quando ainda aprendiam as bases da história clínica, lidando, portanto, com algumas dificuldades para entrevistar pacientes. O fato dos métodos qualitativos utilizarem entrevistas como instrumentos para coleta de dados foi percebido como uma oportunidade de aprendizado a mais desta habilidade clínica, ao contrário do que aconteceria caso o instrumento de coleta fosse estruturado na forma de questionários fechados.

Quando a coleta de dados ocorreu com profissionais de saúde, a interação que os estudantes já vinham tendo com as USF, em suas atividades curriculares, foi percebida como particularmente útil, pois já se tinha experiência de conviver com os profissionais dessas unidades e com as políticas de saúde implementadas nesses serviços. 
A oportunidade, relativamente precoce, de conversar com pacientes (colhendo histórias de vida e histórias clínicas) e com o pessoal dos serviços de saúde facilitou, no entender dos estudantes, a realização da IC, permitindo uma sensação de maior proximidade com quem mais tarde poderia vir a ser um entrevistado da pesquisa.

\section{(6) Preparação do corpus (conjuntos de entrevistas)}

A preparação do corpus (conjunto de entrevistas realizadas para cada pesquisa, reunidas para serem analisadas) foi etapa do processo investigatório, que não suscitou dificuldades especiais, embora a transcrição praticamente literal das entrevistas tenha sido percebida pelos estudantes como muito trabalhosa.

\section{(7) Contato intensivo e redução dos dados empíricos "brutos"}

Foram percebidas dificuldades especiais nesta etapa, gerando a sensação de maior dependência em relação aos orientadores. Para análise dos dados coletados, era necessário categorizá-los por relevância teórica ou reiteração, etapa descrita como muito difícil pelos estudantes. As possibilidades analíticas foram vistas como ricas e, as entrevistas, como contendo uma gama excessiva de dados a serem explorados.

Na leitura das entrevistas transcritas para separar os núcleos de sentido e os temas a partir dos enunciados proferidos pelos entrevistados, a participação dos orientadores foi percebida como ainda mais indispensável, devido às dificuldades dos estudantes em "passar para o papel" o que se pensou e em organizar as categorias e os elementos que eram destacados.

Nas pesquisas que envolveram pré-categorias analíticas definidas no projeto, percebeu-se que na análise das entrevistas esses grandes temas já previstos se "desdobraram", tornando mais complexa a análise, principalmente quanto aos discursos percebidos como mais subjetivos.

Esta fase foi percebida como uma "entrada" na compreensão do mundo psicológico, cultural e social dos entrevistados, um passo inicial à procura de interpretar suas falas e atitudes. Por esses motivos, este momento foi visto como instigante, estimulando o estudo do assunto para conseguir "enxergar nas entrelinhas" dos dados.

\section{(8) Formulações teóricas a partir dos dados organizados}

Os estudantes perceberam esta etapa como a de maior dificuldade, pois fez emergirem suas limitações e inexperiências com o tipo de movimento interpretativo requerido nas pesquisas qualitativas. Na prática, percebeu-se que os orientadores se ocuparam com este momento da pesquisa, pois, apesar dos estudantes terem estudado sobre o tema pesquisado, os modelos teórico-interpretativos envolvendo conhecimentos de ciências humanas foram percebidos como pouco dominados, dificultando análises e interpretações mais críticas.

Os estudantes perceberam-se, deste modo, como participantes mais passivos nesta etapa, detendo-se, por vezes, mais em avaliar e validar as elaborações dos orientadores do que em fazer intervenções e acréscimos. Algumas vezes, a percepção de alguns estudantes é de que seriam incapazes de expressar por escrito "o que se conseguiu extrair" dos dados empíricos, sentindo que, por si sós, fariam interpretações de senso comum, não-fundamentadas em conhecimentos científicos.

O caráter exploratório, muitas vezes heurístico, das pesquisas qualitativas em saúde (que, em várias investigações, terminam por teorizar diretamente sobre o que foi coletado - "grounded theories" ou "teorias fundamentadas em dados" - e menos a partir de elaborações anteriores) parece favorecer este tipo de avaliação dos estudantes. A interpretação dos dados é percebida, então, como a parte mais difícil da pesquisa qualitativa, prevalecendo a ideia, entre os estudantes, de que não detêm um repertório teórico suficiente para interpretar os enunciados.

Entretanto, outro movimento do processo interpretativo, aquele que diz respeito ao diálogo que se estabelece com as formulações teóricas já presentes na literatura, foi percebido como mais acessível, isto é, comparar os resultados da pesquisa em que participou com os já existentes na literatura.

Ao final da pesquisa, quando alguns estudantes perceberam que as categorias estavam interpretadas, deram-se conta de que correspondiam à resposta para a questão da pesquisa, gerando com isso uma sensação de satisfação, pois enxergaram na discussão feita um conteúdo rico, com potencial para ajudar a melhorar a prática médica.

\section{(9) Redação dos relatórios de pesquisa e divulgação dos resultados}

Os relatórios de pesquisa entregues às agências financiadoras não representaram dificuldades, aos olhos dos estudantes. Isto se deveu ao prazo de entrega destes relatórios (um ano depois de iniciados os trabalhos), tendo sido, portanto, relatórios parciais, em que não se propunha uma interpretação elaborada dos achados (fase, como se observou, considerada das mais difíceis). A mesma lógica parece presente quanto à apresentação oral dos resultados parciais no congresso locorregional de IC da Universidade, também considerado um percurso sem maiores dificuldades. 
Diante da necessidade da redação de artigos, para uma divulgação mais ampla dos achados, de modo geral, os estudantes perceberam-se inseguros quanto ao estilo de redação científica necessário. Tal insegurança também ocorreu em razão do volume dos achados em cada pesquisa, que exigem exposições longas dos resultados ou, então, da necessidade de sintetizar demasiadamente. As dificuldades também disseram respeito a encontrar um caminho para desenvolver a argumentação - ou seja, para a interpretação dos achados, no que pese a impressão dos alunos de se dispor de um material inédito para discussão e, assim, ter segurança para discorrer adequadamente sobre o assunto.

Quanto a este tópico específico, vale uma menção aos conhecimentos teóricos prévios dos estudantes na área de Ciências Humanas. Os estudantes não consideram, de modo geral, que as disciplinas e demais atividades educacionais cursadas nos Ensinos Fundamental e Médio tenham beneficiado de modo específico nos seus trabalhos de IC. De modo apenas inespecífico, valorizou-se o estilo de estudar promovido por algumas escolas que incentivam a busca de informações. Como contraponto, reconhece-se o valor da disciplina de Português e Redação, percebida como tendo sido útil ao desenvolvimento da habilidade de compreender os textos estudados, fazer os fichamentos e redigir claramente as hipóteses, quando foi o caso. Isso é compreensível à medida que os dados com que as pesquisas qualitativas trabalham não são formados por "números", mas sim por "letras" - nas expressões utilizadas por Pires ${ }^{13}$ assim como seus resultados e conclusões são elaborações e construções semânticas, tal valorização é compreensível.

\section{Comentários finais}

Atualmente, os currículos dos Ensinos Fundamental e Médio ainda não enfatizam as Ciências Humanas, sendo razoável esperar que os alunos cheguem aos cursos de graduação com um background de conhecimentos teóricos aquém do ideal nesta área. Esta foi, segundo a presente experiência, a principal dificuldade ao desenvolvimento de estágios de IC por meio de projetos de pesquisa com uso de métodos qualitativos.

Esta experiência, como professores e alunos, também indica que, uma vez capacitados em relação às bases metodológicas das abordagens qualitativas em saúde e à técnica de entrevista com questões abertas, os estudantes tiveram suficientemente autonomia para executar a pesquisa de campo. Porém, para realizar a análise e interpretação dos achados, necessitaram de orientação mais próxima dos orientadores, tanto em relação às questões biomédicas presentes nos dados coletados, quanto, sobretudo, em relação aos referenciais teórico-interpretativos das Ciências Humanas.
A despeito das dificuldades relatadas, os professores perceberam como altamente motivadora a oportunidade de contribuir para a formação de médicos com uma visão ampla, amadurecida e qualificada da ciência e da metodologia científica. Sentem-se investindo em recursos humanos e contribuindo para a formação de jovens cidadãos mais críticos.

Os estágios de IC com pesquisas qualitativas foram considerados, por todos, como úteis para o aperfeiçoamento de importantes habilidades médicas, como a realização de entrevistas. Por meio desses estágios, acredita-se valorizar-se também a rede de significados individuais e coletivos presentes no processo saúde-doença-cuidado, e a compreensão dessa rede potencialmente ajuda a aperfeiçoar uma prática médica efetivamente atenta às plenas necessidades dos pacientes. Embora somente três dos sete projetos de pesquisa tenham envolvido a APS, considera-se que esses ganhos sejam particularmente úteis para uma futura prática médica nesse cenário clínico, haja vista a peculiar complexidade da assistência que é prestada em tal nível da atenção à saúde.

\section{Referências}

1. Tenório MDP, Beraldi G. Iniciação científica no Brasil e nos cursos de medicina. Rev Assoc Med Bras. 2010; 56(4): 390-3. http://dx.doi. org/10.1590/S0104-42302010000400007

2. Ministério da Educação. Instituto Nacional de Pesquisas e Estudos Educacionais Anísio Teixeira (Inep). Informativo do Inep. 2005; 3(98) [Internet] [acesso em 2011 Set 19]. Disponível em: http://www.inep.gov. br/informativo/informativo98.htm

3. Oliveira NAD, Alves LA, Luz MR. Iniciação científica na graduação: o que diz o estudante de medicina? Rev Bras Educ Med. 2008; 32(3): 309-14. http://dx.doi.org/10.1590/S0100-55022008000300005

4. Cardoso GP, Silva Junior CTD, Carvalho Netto ALDC, Touça ADS, Brigido DC, Mattos ACMTD, et al. Visão geral de um Programa de Iniciação Científica em medicina: experiência do Curso de Medicina da Universidade Federal Fluminense. Pulmão RJ. 2004; 13(3): 174-81.

5. Cardoso GP, Silva Junior CTD, Martinho J, Cyrillo R. Iniciação científica em medicina: uma questão de interesse para todas as especialidades. Pulmão RJ. 2004; 13(1): 8-12

6. Jacobs CD, Cross PC. The value of medical student research: the experience at Stanford University School of Medicine. Med Educ. 1995; 29(5): 342-6. http://dx.doi.org/10.1111/j.1365-2923.1995.tb00023.x

7. Montes G. Da importância de uma disciplina de iniciação científica ao currículo nuclear na graduação em medicina na USP. Rev Bras Cardiol. 2000; 2(2): 70-7

8. Crasto M, Neves D, Pires M, Nascimento L, Vieira L, Serafim E. O ensino de iniciação científica de graduação em medicina. Pulmão RJ. 2007; 16(1): 12-6.

9. Hydén L. IIIness and narrative. Sociol Health IIIn. 1997; 19(1): 48-69. http:// onlinelibrary.wiley.com/doi/10.1111/j.1467-9566.1997.tb00015.x/pdf

10. Bury M. IIIness narratives: fact or fiction? Sociol Health IIIn. 2001; 23(3): 263-85. http://dx.doi.org/10.1111/1467-9566.00252

11. Minayo MCDS. O desafio do conhecimento: pesquisa qualitativa em saúde. $12^{a}$ ed. São Paulo: Hucitec; 2010. 408 p.

12. Fontanella BJB, Luchesi BM, Saidel MGB, Ricas J, Turato ER, Melo DG. Amostragem em pesquisas qualitativas: proposta de procedimentos para constatar saturação teórica. Cad Saúde Pública. 2010; 27(2): 388-94. http://dx.doi.org/10.1590/S0102-311X2011000200020

13. Pires AP. Amostragem e pesquisa qualitativa: ensaio teórico e metodológico. In: Vários autores, organizador. A pesquisa qualitativa: enfoques epistemológicos e metodológicos. Petrópolis: Vozes; 2008. p. 154-211. 